\title{
The Effects of Scientific Inquiry Simulations on Students' Higher Order Thinking Skills of Chemical Reaction and Attitude towards Chemistry
}

\author{
Bilal Khaleel Younis* \\ Technology Education Department, Palestine Technical University Khadoorie- Arroub branch, Hebron, Palestine \\ *Corresponding author: byounis@ptca.edu.ps
}

\begin{abstract}
This study investigated the effects of scientific inquiry simulations on higher order thinking skills and attitudes of chemical reaction. A mixed method approach was implemented; an experimental pre-test post-test and a focus group were conducted to collect data. Seventy-six students from $9^{\text {th }}$ grade were randomly assigned to the experimental and control group. Thirty-eight students participated in each group. A Higher Order Thinking Skills Exam, a Chemistry Attitude Scale and a Scientific Inquiry Worksheet were used for data collection. A focus group was also conducted with ten students from each group to shed more light on the findings. The results showed that the post-test scores and attitudes of students who were taught with scientific inquiry simulations were found to be higher than those in the control group who were taught with scientific inquiry activities. The findings support the notion that chemistry teachers should be supported to use scientific inquiry simulations for teaching chemistry.
\end{abstract}

Keywords: scientific inquiry, simulations, higher order thinking skills, chemical reaction

Cite This Article: Bilal Khaleel Younis, "The Effects of Scientific Inquiry Simulations on Students' Higher Order Thinking Skills of Chemical Reaction and Attitude towards Chemistry." American Journal of Educational Research, vol. 5, no. 11 (2017): 1158-1161. doi: 10.12691/education-5-11-7.

\section{Introduction}

Information and communication technology is important in our daily lives; it has affected every aspect of our society. Around the world, the educational systems try to integrate technology in classroom activities to overcome the difficulties that hinders students from getting active learning. Among the ICT tools that teachers in developing countries use in teaching science are simulations. Teachers can use simulations to enhance learning through omitting some elements of real world phenomena to make it simpler for students to understand. Instructional simulations can also help students test their hypothesis and predict the results of their actions and get immediate feedback in a scientific context [1].

Chemistry is an important subject in the Palestinian curriculum. Students can see chemistry, and it is applications in everything surrounded them. However, students fail to understand the chemical phenomenon and connect what they learn at school with life. One of the main objectives of chemistry is to help students write correct chemical equations and know the evidence of chemical reaction occurrence. However, students usually find it difficult to understand "rate of chemical reaction" since it is an abstract concept and they usually have misconceptions [2].

\section{Theoritical Perspective}

Chemical reactions are abstract concepts, and teachers considered them among the most difficult subjects to teach. Recently, science educators use scientific inquiry to help students build their mental models by asking questions, planning solutions, testing hypothesis, and reflecting on their constructed knowledge [3]. Therefore, scientific inquiry could help students achieve better learning and reach higher order thinking skills when learning chemical reactions.

Literature shows that educational simulations have positive impact on students' learning $[4,5,6]$. Literature also revealed that students can achieve better learning if learners engage in "deep knowledge construction" when using educational simulations [7]. Olakanmi [8] found that students who learned chemical reaction by computer simulations scored better achievement and developed higher motivation than students who used traditional method. Therefore, educational simulations could help in the scientific inquiry learning process since they allow students to observe scientific phenomena, write hypothesis and test them, conduct virtual experiments, measure variables, and construct results.

Simulation software that teachers usually use in teaching chemistry is "Crocodile Chemistry". The software was designed for individual use, as well as group 
demonstration. The user can use glassware, chemicals, and equipment tools to combine and watch chemical reactions.

This research will use scientific inquiry simulations for teaching chemistry in the Palestinian context. It is thought to be important, since it will clarify for teachers how to use Crocodile Chemistry Software to develop educational simulations and specifically scientific enquiry simulations. It will also develop a model for teachers to follow to improve students' higher order thinking skills when learning chemical reactions.

\section{Research Aim}

The purpose of this research is to develop, implement, and evaluate scientific inquiry simulations derived from the Palestinian curriculum and investigate their effects on students' higher order thinking skills when learning chemical reaction. The research attempts to answer the following research questions: Q1. How do proposed scientific inquiry simulations affect students' higher order thinking skills when learning chemical reaction? Q2. How do proposed scientific inquiry simulations affect students' attitudes when learning chemical reaction?

\section{Methodology}

\subsection{Research Design}

A mixed method approach was used in this research; an experimental pre-test post-test design was implemented to collect quantitative data and a focus group was conducted to collect qualitative data.

\subsection{Sampling}

Students from Raqa school in Palestine participated in this study. The sample represented the entire population of students in the 9th grade. Seventy-six students were randomly assigned to the experimental and control group. Thirty eight students participated in each group.

\subsection{Instruments}

For the purposes of this research, a Higher Order Thinking Skills Exam, a Chemistry Attitude Scale and a Scientific Inquiry Worksheets were developed. The developments of the instruments are now described.

The researcher, a science supervisor, and a teacher used Crocodile Chemistry Software to design four scientific inquiry simulations derived from the school curriculum. The simulations were piloted in another school before they used in this study. These simulations were used to teach chemical reaction for the experimental group. The participants in the experimental group were asked to run each simulation and answer a scientific inquiry worksheet. The control group participants were asked to use worksheets and conduct scientific inquiry activities. At the beginning and the end of the experiment, both groups participated in the Higher Order Thinking Skills Exam and the Chemistry Attitudes Scale. At the end of the learning sessions, two focus group were conducted with 10 students from each group. "Think aloud" protocol was used to help the participants verbalize what they were thinking and feeling throughout their experience.

\section{Data Analysis}

\subsection{Students' Achievement Prior to the Study}

A t-test was used to evaluate scientific inquiry simulations effectiveness on students' higher order thinking skills. The academic performance of the experimental group (scientific inquiry simulations) was compared to the control group (scientific inquiry activities) before participating in the experiment. An independent sample t-test was conducted to assess whether a significant difference in higher order thinking skills scores between the experimental and control groups on the pretest. The results are presented in Table 1 .

Table 1. t-test results comparing experimental group and control group on higher order thinking skills pre-test.

\begin{tabular}{ccccc}
\hline Group & $\mathrm{N}$ & Mean & Std. Deviation & t-test \\
\hline Experimental & 38 & 15.26 & 4.37 & .731 \\
Control & 38 & 14.57 & 3.76 & \\
\hline$* \mathrm{P}>.05$. & & & &
\end{tabular}

An independent sample t-test was also conducted to assess whether a significant difference in chemistry attitudes scores between the experimental and control groups prior to the research. The results are presented in Table 2 .

Table 2. t-test results comparing experimental group and control group on chemistry attitudes before participating in the research

\begin{tabular}{ccccc}
\hline Group & $\mathrm{N}$ & Mean & Std. Deviation & t-test \\
\hline Experimental & 38 & 3.84 & .199 & 1.03 \\
Control & 38 & 3.71 & .240 & \\
\hline
\end{tabular}

$* \mathrm{P}>.05$.

The results show that there are no significant differences in students higher order thinking skills on chemical reactions as well as attitudes towards chemistry before participating in this study, $\mathrm{t}(38)=.731, p>0.05$ for higher order thinking skills in chemical reaction. For chemistry attitudes, the results were $\mathrm{t}(38)=1.03, p>0.05$. The results reveal that the experimental and control group were at the same level before participating in the study.

\subsection{Students' Achievement after the Study}

An independent sample t-test was conducted to assess whether significant difference in higher order thinking skills scores between the experimental and control groups after participating in the research. The results are presented in Table 3.

Table 3. t-test results comparing experimental group and control group on higher order thinking skills post-test.

\begin{tabular}{ccccc}
\hline Group & $\mathrm{N}$ & Mean & Std. Deviation & t-test \\
\hline Experimental & 38 & 63.68 & 18.25 & \multirow{2}{*}{4.43} \\
Control & 38 & 44.73 & 18.99 & \\
\hline
\end{tabular}

$* \mathrm{P}<.05$. 
Table 3 shows that a significant difference between the experimental group and the control group in higher order thinking skills, in favor of scientific inquiry simulations, $t$ $(38)=4.43 ; p<0.05$. This result suggests that scientific inquiry simulations have better impact on students' higher order thinking skills of chemical reaction than classroom scientific inquiry activities.

An independent sample t-test was also conducted to assess whether significant difference in chemistry attitudes scores between the experimental and control groups after participating in this research.

Table 4. t-test results comparing experimental group and control group on chemistry attitudes after participating in the research

\begin{tabular}{ccccc}
\hline Group & $\mathrm{N}$ & Mean & Std. Deviation & t-test \\
\hline Experimental & 38 & 4.27 & .168 & 3.41 \\
Control & 38 & 3.81 & .756 & \\
\hline
\end{tabular}

$* \mathrm{P}<.05$.

Table 4 show that a significant difference exists between the experimental group and the control group on chemistry attitudes, in favor of scientific inquiry simulations, $\mathrm{t}(38)=3.41 ; p<0.05$. This result suggests that scientific inquiry simulations have better impact on students' attitudes than classroom scientific inquiry activities.

\subsection{Focus Group Results}

A focus group was conducted with ten students from each group in this study. The focus group results were analyzed alongside the finding of the t-test to shed more light on the major finding. The questions participants were asked, and a summary of their responses follows.

Question 1: Do you think it is easy for students to learn by scientific inquiry? Why or why not?

The majority $(80 \%)$ of the focus group participants from the experimental group who learned by scientific inquiry simulations believed that students could use scientific inquiry simulations efficiently. One of the students said, "our teacher showed us how to use the simulations before we started using them, this helped us a lot since it is the first time we use Crocodile Chemistry". Another student added. "I was ready to interact with this activity since I have computer at home."

The control group, who learned by scientific inquiry activities, also found it easy to conduct their scientific inquiry activities. Most of them the focus group participants from the control group $(70 \%)$ revealed that they were used to use their chemistry lab for chemistry experiments.

Question 2: What are the obstacles that you faced in learning by scientific inquiry? Explain.

A majority (70\%) of the focus group participants in the scientific inquiry activities had a view that the school science lab is not suitable for conducting scientific inquiry experiments individually. A student mentioned, "I was watching my group working on the experiment and did nothing to help them." Another student said, "our teacher did one of the experiments in front of us; the whole class was just watching him and answering their worksheets." Otherwise, the participants in the scientific inquiry simulations did not state any problem.

Questions 3: What are the benefits that you gained from learning by scientific inquiry? Explain.
Most of the participants in the scientific inquiry simulations focus group (90\%) mentioned that learning chemistry was enthusiastic. Each student was able to conduct his experiment and repeat it several times to get the required results. One of the students said, "I was happy because I could conduct dangerous experiments safely".

The participants in the scientific inquiry activities were also excited in conducting their activities. Most of them (70\%) were happy to sense the change in temperature and color of the chemical compounds.

\section{Discussion}

This study investigated the effect of scientific inquiry simulations on higher order thinking skills of chemical reaction and attitude of students toward learning chemistry. The post-test scores of students who were taught with scientific inquiry simulations were found to be higher than those in the control group who were taught with scientific inquiry activities $(\mathrm{t}(38)=4.43, \mathrm{p}<0.05)$. This result is supported by Westho, Bergman \& Carroll [9], Aktas, Bulut \& Yuksel [10], Karacop \& Doymus [11], and Olakanmi [8] who found in their studies that computer simulations have positive impact on students achievement compared to traditional teaching methods. The researcher proposed this result to some advantages of the scientific inquiry simulations. These benefits are: students who use simulations to conduct scientific inquiry focus more on the process in place of the material and the equipment [12]. They also perform their inquiry in a safe experimental environment and conduct the experiments individually as given from the focus group results.

This study results also showed a positive impact of scientific inquiry simulations on students' attitudes towards learning chemistry $(\mathrm{t}(38)=3.41, \mathrm{p}<0.05)$. This result was also supported by Olakanmi [8] and Hwang, Wu \& Ke (2011) [13] studies. The focus group could explain this result; the students who learned by scientific inquiry simulations mentioned that they were excited doing their activities. The result could be because the simulations were attractive and suitable learning environment for the age group.

Even though, the present study has found that scientific inquiry simulations are better than scientific inquiry activities in promoting higher order thinking skills and attitudes toward chemical reaction. Teachers should combine both methods in their learning environments to get benefit from each method characteristics. Scientific inquiry simulations are better used when the inquiry is dangerous, and the apparatus are not available. Scientific inquiry activities are better used when it is necessary for the students to sense the change in temperature and color of the chemical compounds.

\section{Conclusion and Implementation}

In conclusion, the present study has found that scientific inquiry simulations are effective learning environments for promoting students' higher order thinking skill and attitudes toward chemical reaction. This finding provides teachers, administrators, and stakeholders 
with research results that support integrating simulations in teaching science at school level. It will also enable curriculum designers to integrate simulations in science curriculum combined with learning strategies that support active involvement of students.

Given the research results, it is recommended that science teachers should be supported to integrate simulations in classroom activities. Simulations and various technological tools should be included in preservice and in-service training programs. Further simulations combined with other strategies should be researched among students from different subjects to enable generalizing the finding of this research and increasing it is validity.

\section{References}

[1] Granland R., Bergland, E., \& Eriksson, H. (2000). Designing webbased simulation for learning. Future Generation Computer Systems, 17, 171-185.

[2] Çakmakçı, G., Leach, J., \& Donnelly, J. (2006). Students' ideas about reaction rate and its relationship with concentration or pressure. International Journal of Science Education, 28 (15), 1795-1815.

[3] Linn, M. C. (2000). Designing the knowledge integration environment. International Journal of Science Education, 22 (8), 781-796.

[4] Chen, C., \& Howard, B. (2010). Effect of live simulation on middle school students' attitudes and learning toward science. Journal of Educational Technology and Society 13 (1), 133-139.
[5] Chang, H. Y., Quintana, C., \& Krajcik, J. S. (2010). The impact of designing and evaluating molecular animations on how well middle school students understand the particulate nature of matter. Science Education, 94 (1), 73-94.

[6] Chien, Y. T., \& Chang, C. Y. (2012). Comparison of different instructional multimedia designs for improving student scienceprocess skill learning. Journal of Science Education and Technology, 21 (1), 106-113.

[7] Wong, R. M. F., Lawson, M. J., \& Keeves, J. (2002). The effects of self-explanation training on students' problem solving in high school mathematics. Learning and Instruction, 12, 233-262.

[8] Olakanmi, E. E. (2015). The effects of a web-based computer simulation on students' conceptual understanding of rate of reaction and attitude toward science. Journal of Baltic Science Education, 14, (5), 627-639.

[9] Westho, B. W., Bergman, D., \& Carroll, J. (2010). The Effects of Computer Animations on High School Students Performance and Engagement in Biology. Paper presented at the 6th Annual GRASP Symposium, Wichita State University.

[10] Aktas, M., Bulut, M., \& Yuksel, T. (2011). The effect of using computer animations and activities about teaching patterns in primary mathematics. The Turkish Online Journal of Educational Technology, 10 (3), 273-277.

[11] Karacop, A., \& Doymus, K. (2013). Effects of jigsaw cooperative learning and animation techniques on students' understanding of chemical bonding and their conceptions of the particulate nature of matter. Journal of Science Education and Technology, 22 (2), 186-203.

[12] Tatli, Z., \& Ayas, A. (2013). Effect of a Virtual Chemistry Laboratory on Students' Achievement. Educational Technology \& Society, $16(1), 159-170$

[13] Hwang, G. J., Wu, P. H., \& Ke, H. R. (2011). An interactive concept map approach to supporting mobile learning activities for natural science courses. Computers \& Education, 57 (4), $2272-2280$. 